\title{
Cellular profile of bronchoalveolar lavage fluid in Turkish miners
}

\author{
O Kayacan, S Beder, D Karnak
}

Postgrad Med J 2003;79:527-530

See end of article for authors' affiliations

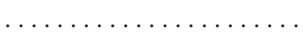

Correspondence to: Professor Oya Kayacan, Ankara University, School of Medicine, Chest

Diseases Department,

Cebeci, 06100 Ankara,

Turkey;

kayacan@

medicine.ankara.edu.tr

Submitted 11 March 2003 Accepted 22 May 2003

\begin{abstract}
Pneumoconiosis is still a health problem in Turkey and has a relatively high incidence. Retired underground miners were investigated to document alveolitis, and to observe the difference in the cellular profiles of bronchoalveolar lavage (BAL) fluid with or without pneumoconiosis.

Twenty nine retired male miners and 17 controls, eight non-smokers (four male, four female) and nine smokers (six male, three female), without any dust exposure were evaluated. According to the International Labor Office 1980 classification system, the miners were allocated to three subgroups: eight without pneumoconiosis, 11 with simple pneumoconiosis, and 10 with progressive massive fibrosis (PMF). Spirometric tests and arterial blood gases analysis were done and fibreoptic bronchoscopy and BAL were performed in all subjects.

The study and the control subjects were comparable in respect to age, smoking habits, except the non-smoker controls, and the duration of dust exposure, except the controls. The amount of recovered BAL fluid was lower in all miners compared with the non-smoker controls $(p<0.05)$. The amount of recovered BAL fluid and the total cell count correlated significantly $(r=0.48, p<0.01)$. The percentage of lymphocytes in the BAL fluid of miners without pneumoconiosis and with PMF $(p<0.05)$ and that of simple pneumoconiosis $(p<0.01)$ was significantly lower compared with the non-smoker controls.

Alveolitis was not a representative feature of Turkish subjects with an occupational history of underground mining, and BAL fluid cellular profile did not seem to be different in miners with or without pneumoconiosis.
\end{abstract}

$\mathrm{P}$ neumoconiosis is a diffuse lung disease associated with occupational exposure to inorganic dust and minerals. The important factors in this group of diffuse lung diseases are the quantity and the quality of the dust exposed and the duration of exposure defined as the number of working days in a mine. Among the miners exposed to similar inorganic dust with a similar concentration, some never develop pneumoconiosis while some others develop simple pneumoconiosis with small nodules seen on chest radiographs or complicated pneumoconiosis/progressive massive fibrosis (PMF) with large opacities besides the small ones. ${ }^{1}$

The diagnosis is based on the occupational history and the chest radiography findings consistent with pneumoconiosis according to International Labor Office standards. ${ }^{2}$ Bronchoscopy and bronchoalveolar lavage (BAL) are not routinely performed in such patients. However, the following are the indications for performing BAL in patients with suspected pneumoconiosis:

1. The exclusion of other causes of diffuse lung disease, such as sarcoidosis, tuberculosis, pulmonary haemorrhage syndromes, malignancies, etc, in patients additionally exposed to inorganic dust.

2. The documentation of mineral dust exposure in patients who may not be aware of being at increased risk of dust inhalation.

3. The documentation of the local immune and inflammatory reaction - that is, alveolitis. ${ }^{3}$

Pneumoconiosis is still a health problem in our country with a relatively high incidence of $12 \%{ }^{4}$ and those with pneumoconiosis have not been evaluated previously by bronchoscopy and BAL. We performed fibreoptic bronchoscopy and BAL in retired underground miners seeking medicolegal help claiming to have pneumoconiosis.

We conducted a clinical trial to document alveolitis in miners, if any, and to observe the differences in the cellular profiles of BAL fluid of miners exposed to inorganic dust but who had not developed pneumoconiosis and those with different categories of pneumoconiosis.

\section{SUBJECTS AND METHODS}

\section{Study and control subjects}

Twenty nine retired miners, all males, were evaluated. Twenty six were coal workers, two were antimony miners, and one was a lead-zinc miner. The subjects in the study group were allocated to three subgroups: eight without pneumoconiosis, 11 with simple pneumoconiosis, and 10 with PMF. Eight nonsmokers (four males, four females) and nine smokers (six males, three females) without any dust exposure served as controls.

Gender, age, smoking habits of the study subjects and controls and the duration of dust exposure of the miners were registered. Posteroanterior chest radiographs were taken, spirometric tests and arterial blood gases analysis were done, and fibreoptic bronchoscopy and BAL were performed in all subjects. Control subjects had undergone fibreoptic bronchoscopy for haemoptysis or cough work-up. They have been followed up thereafter for one year and no disease was detected. Informed oral consent was obtained from all study subjects. This study has been approved by the local ethical committee.

\section{Chest radiographs}

Posteroanterior chest radiographs were evaluated according to the International Labor Office 1980 classification system ${ }^{2}$ by a consensus of three trained readers. Briefly, there are two major types of parenchymal opacities: large $(>10 \mathrm{~mm})$ and small.

Abbreviations: $\mathrm{BAL}$, bronchoalveolar lavage; $\mathrm{FEV}_{1}$, forced expiratory volume in the first second; FVC, forced vital capacity; PMF, progressive massive fibrosis 
Table 1 Characteristics of the study subjects

\begin{tabular}{llllll}
\hline & $\begin{array}{l}\text { Gender } \\
(M: F)\end{array}$ & Age (years) & $\begin{array}{l}\text { Smoking } \\
\text { habits } \\
\text { (pack-years) }\end{array}$ & Type of work & $\begin{array}{l}\text { Duration of } \\
\text { exposure } \\
\text { (years) }\end{array}$ \\
\hline Non-smoker controls $(n=8)$ & $4: 4$ & $42.8(13.3)$ & - & - & - \\
Smoker controls $(n=9)$ & $6: 3$ & $43.3(7.6)$ & $21.1(9.2)$ & - & - \\
Miners without pneumoconiosis $(n=8)$ & $8: 0$ & $52.8(8.9)$ & $22.1(15.0)$ & Coal worker & $11.9(8.8)$ \\
Simple pneumoconiosis $(n=11)$ & $11: 0$ & $54.1(8.9)$ & $11.5(16.3)$ & Coal worker & $15.3(8.1)$ \\
Progressive massive fibrosis $(n=10)$ & $10: 0$ & $50.5(12.8)$ & $32.4(46.0)$ & 7 coal workers, 2 antimony miners, 1 lead-zinc miner $25.0(6.8)$ \\
\hline
\end{tabular}

Small opacities are classified on the basis of shape and size. Rounded and irregular opacities are categorised according to size: $\mathrm{p}(\mathrm{s})<1.5 \mathrm{~mm}, \mathrm{q}(\mathrm{t}) \mathrm{1.5}-3$, and r $(\mathrm{u}) 3-10 \mathrm{~mm}$. The profusion of small opacities is rated on a 12 category scale ranging from $0 / 0$ to $3 / 3$. Large opacities are classified on the basis of diameter: A, $1-5 \mathrm{~cm} ; \mathrm{B},>5 \mathrm{~cm}$ or less than the right upper lobe area; and C, greater than the right upper lobe area. Miners with only small opacities were classified as having simple pneumoconiosis and those with large opacities besides the small, as having progressive massive fibrosis (PMF). ${ }^{1}$

\section{Spirometric tests}

Spirometric evaluation of the study subjects was done on a Vitalograph alpha spirometer. Forced vital capacity (FVC), forced expiratory volume in the first second $\left(\mathrm{FEV}_{1}\right)$ and $\mathrm{FEV}_{1} /$ FVC ratio were measured.

\section{Arterial blood gas analysis}

Arterial blood samples were analysed by ABL300. Partial pressures of oxygen and carbon dioxide and oxygen saturation were measured.

\section{Fibreoptic bronchoscopy and BAL procedure}

After one night fasting, subjects were premedicated with atropine $1 / 4 \mathrm{mg}$ subcutaneously and topically anaesthetised by inhaling $2 \%$ prilocaine through a nebuliser. The bronchoscope was inserted transorally and after having examined the tracheobronchial tree thoroughly, it was wedged into the right middle lobe. Five aliquots of $20 \mathrm{ml}$ of $0.9 \%$ saline solution at room temperature was instilled and immediately retrieved with a hand-held syringe. The dwell time was assessed as zero. The amounts of instilled and recovered fluid were registered. BAL fluid was studied as previously described. ${ }^{3}$ The recovered BAL fluid was filtered through three layers of gauze and centrifuged at $400 \mathrm{~g}$ for 10 minutes and the supernatant was removed. The pellet was resuspended in $2 \mathrm{ml}$ of balanced Hank's solution. Cell count and vitality tests were carried out on a Neubauer's camera by using Turk's solution and trypan blue respectively. The differential count was done on smears stained with May-Grünwald-Giemsa by counting at least 600 cells on each slide. BAL findings were expressed both as the percent of the total cells and absolute number of cells per ml of recovered BAL fluid.

\section{Statistics}

The statistical analysis was carried out on a PC by the SPSS program (version 8.0). All data were expressed as the mean (SD), and comparison between the groups was done by multiple variance analysis. For the correlation analysis Pearson's test was applied. Any p value less than 0.05 was considered significant.

\section{RESULTS}

The study subjects were comparable in respect to age, smoking habits, and the duration of dust exposure. The characteristics of the study subjects are shown in table 1 .

Eight non-smokers and nine smokers served as the controls and were comparable with the study subjects with respect to age; the smoking habits of the study subjects were also comparable to the smoker controls. The retired miners were comparably exposed to inorganic dust, while the controls were free from any dust exposure at the risk of pneumoconiosis.

The spirometric test results of the subjects can be seen in table 2. The FVC $(p<0.01)$ and $\mathrm{FEV}_{1}(\mathrm{p}<0.001)$ of the miners without pneumoconiosis were significantly lower compared with both control groups. The FEV of the subjects with PMF was significantly lower compared with non-smoker controls $(\mathrm{p}<0.001)$. FVC, $\mathrm{FEV}_{1}$, and $\mathrm{FEV}_{1} / \mathrm{FVC}$ were conversely correlated with the duration of exposure $(r=-0.42, \mathrm{p}<0.05 ; r=$ $-0.56, \mathrm{p}<0.0 \mathrm{l} ; r=-0.43, \mathrm{p}<0.05$, respectively).

The results of the arterial blood gases analysis documented a slight hypoxaemia without any statistical significance in miners (table 2). The partial pressures of carbon dioxide in all subjects were in normal range; however, that of PMF patients were significantly higher than the non-smoker controls, without any clinical relevance.

The amount of normal saline instilled did not differ between the groups. However, the amount of recovered BAL fluid was lower in miners with or without pneumoconiosis compared with the non-smoker controls $(\mathrm{p}<0.05)$ (table 3$)$. The amount of recovered BAL fluid and the total cell count correlated significantly $(r=0.48, \mathrm{p}<0.01)$.

The total cell count of BAL fluid and the percentage of alveolar macrophages were higher in miners compared with

Table 2 Spirometric test and arterial blood gases analysis results

\begin{tabular}{|c|c|c|c|c|c|c|}
\hline & FVC & $\mathrm{FEV}_{1}$ & $\mathrm{FEV}_{1} / \mathrm{FVC}$ & $\mathrm{PaO}_{2}$ & $\mathrm{PaCO}_{2}$ & $\mathrm{SaO}_{2}$ \\
\hline Non-smoker controls $(n=8)$ & 101.1 (12.7) & $105.8(14.5)$ & $89.4(4.7)$ & $84.3(7.2)$ & $35.2(4.5)$ & $96.9(1.2)$ \\
\hline Smoker controls $(n=9)$ & $102.0(16.5)$ & $100.9(15.7)$ & $87.4(12.8)$ & 80.5 (11.2) & $33.2(3.2)$ & $95.9(2.0)$ \\
\hline Miners without pneumoconiosis $(n=8)$ & $77.1(17.5)^{*}$ & $70.8(20.7)^{* *}$ & 82.3 (14.9) & $72.3(8.7)$ & $37.0(3.1)$ & $94.7(1.0)$ \\
\hline Simple pneumoconiosis $(n=11)$ & $84.6(13.0)$ & $86.8(14.4)$ & $88.9(12.6)$ & $77.3(5.4)$ & $36.0(1.5)$ & $95.4(1.2)$ \\
\hline Progressive massive fibrosis $(n=10)$ & $101.1(12.7)$ & $75.7(23.3)^{* * *}$ & $83.1(14.5)$ & $71.0(11.8)$ & $36.7(3.1)^{* * * *}$ & $93.4(2.4)$ \\
\hline
\end{tabular}

${ }^{*} \mathrm{p}=0.01$ versus non-smoker and smoker controls; ${ }^{*} \mathrm{p}=0.001$ versus non-smoker and smoker controls; ${ }^{*}{ }^{*} \mathrm{p}=0.001$ versus non-smoker controls;

$* * * * p<0.05$ versus non-smoker controls.

$\mathrm{FEV}_{1}$, forced expiratory volume in the first second; $\mathrm{FVC}$, forced vital capacity; $\mathrm{PaCO}_{2}$, partial pressure of carbon dioxide; $\mathrm{PaO}_{2}$, partial pressure of oxygen; $\mathrm{SaO}_{2}$, oxygen saturation. 
Table 3 Amount of given saline and recovered BAL fluid

\begin{tabular}{|c|c|c|}
\hline & $\begin{array}{l}\text { Amount of given } \\
\text { saline for BAL (ml) }\end{array}$ & $\begin{array}{l}\text { Recovered BAL fluid } \\
\text { ( } \% \text { of given) }\end{array}$ \\
\hline Non-smoker controls ( $n=8$ ) & $100(16.7)$ & $58.8(14.1)$ \\
\hline Smoker controls $(n=9)$ & $105.6(0)$ & $46.2(18.9)$ \\
\hline Miners without pneumoconiosis $(n=8)$ & 102.5 (16.7) & $36.9(14.1)^{*}$ \\
\hline Simple pneumoconiosis $(n=11)$ & $100(0)$ & $37.5(14.6)^{*}$ \\
\hline Progressive massive fibrosis $(n=10)$ & $102.0(6.3)$ & $37.5(15.4)^{*}$ \\
\hline
\end{tabular}

Table 4 BAL fluid findings: total cell count and differentials

\begin{tabular}{llllll}
\hline & $\begin{array}{l}\text { Total cell } \\
\text { count } \\
\left(\times 10^{3}\right)\end{array}$ & $\begin{array}{l}\text { Alveolar } \\
\text { macrophages } \\
(\%)\end{array}$ & $\begin{array}{l}\text { Lymphocytes } \\
(\%)\end{array}$ & $\begin{array}{l}\text { Neutrophils } \\
(\%)\end{array}$ & $\begin{array}{l}\text { Eosinophils } \\
(\%)\end{array}$ \\
\hline Non-smoker controls $(n=8)$ & $5.6(3.4)$ & $80.4(10.0)$ & $12.0(10.3)$ & $6.8(3.9)$ & $1.1(1.3)$ \\
Smoker controls $(n=9)$ & $23.9(31.7)$ & $85.2(8.8)$ & $8.3(5.5)$ & $6.3(6.6)$ & $0.4(0.5)$ \\
Miners without pneumoconiosis $(n=8)$ & $8.1(7.5)$ & $89.2(20.7)$ & $3.5(5.5)^{*}$ & $6.8(14.5)$ & $0.5(0.9)$ \\
Simple pneumoconiosis $(n=11)$ & $8.1(7.6)$ & $94.9(3.5)$ & $1.8(1.3)^{* *}$ & $3.0(3.0)$ & $0.09(0.1)$ \\
Progressive massive fibrosis $(n=10)$ & $8.4(7.4)$ & $85.7(24.4)$ & $3.1(3.0)^{*}$ & $11.2(25.8)$ & $0.4(1.0)$ \\
\hline & & & & & \\
${ }^{*} p<0.05$ versus non-smoker controls. & & & & \\
${ }^{*} \mathrm{p}<0.01$ versus non-smoker controls. & & & & & \\
\hline
\end{tabular}

Table 5 BAL fluid findings: number of cells per $\mathrm{ml}$ of recovered fluid $\left(\times 10^{4} / \mathrm{ml}\right)$

\begin{tabular}{llllll}
\hline & $\begin{array}{l}\text { Total cell } \\
\text { count }\end{array}$ & $\begin{array}{l}\text { Alveolar } \\
\text { macrophages }\end{array}$ & Lymphocytes & Neutrophils & Eosinophils \\
\hline Non-smoker controls $(n=8)$ & $14.7(7.9)$ & $11.4(5.6)$ & $2.1(3.0)$ & $1.3(0.7)$ & $0.1(0.2)$ \\
Smoker controls $(n=9)$ & $33.5(14.5)$ & $24.1(15.6)$ & $2.5(1.4)$ & $1.8(2.6)$ & $0.4(0.9)$ \\
Miners without pneumoconiosis $(n=8)$ & $19.1(16.2)$ & $18.5(16.0)$ & $0.3(0.3)^{*}$ & $0.2(0.2)$ & $0.03(0.07)$ \\
Simple pneumoconiosis $(n=11)$ & $23.0(18.6)$ & $22.5(17.1)$ & $0.4(0.3)^{*}$ & $0.8(1.1)$ & $0.02(0.03)$ \\
Progressive massive fibrosis $(n=10)$ & $21.6(17.9)$ & $16.2(13.9)$ & $0.7(0.9)$ & $4.8(13.8)$ & $0.1(0.3)$ \\
\hline${ }^{*} p<0.05$ versus smoker controls. & & & & & \\
\hline
\end{tabular}

the non-smoker controls, but the differences were not significant (table 4). The percentage of lymphocytes in the BAL fluid of miners without pneumoconiosis and with PMF $(\mathrm{p}<0.05)$ and in those with simple pneumoconiosis $(\mathrm{p}<0.01)$ was significantly lower than the non-smoker controls. The percentage of neutrophil leucocytes was higher in patients with PMF compared with the controls without any significance. The absolute number of lymphocytes was also lower in miners without pneumoconiosis and in those with simple pneumoconiosis compared with the smoker controls $(\mathrm{p}<0.05$, table 5$)$.

\section{DISCUSSION}

Exposure to coal mine dust and/or crystalline silica results in pneumoconiosis with initiation and progression of pulmonary fibrosis. ${ }^{15}$ Coal mine dust exposure may result in several pathological processes, including simple pneumoconiosis and PMF, chronic bronchitis, emphysema, and dust related airflow limitation. ${ }^{6}$ All miners except those with simple pneumoconiosis in the present study had airflow obstruction, and the spirometric parameters correlated positively with the duration of dust exposure.

The effect of dust exposure to gas exchange is unclear. ${ }^{6}$ In this study no significant blood gases analysis changes was detected in miners.

The diagnosis of pneumoconiosis is based on the findings of chest radiography evaluated according to International Labor Office standard films. Bronchoscopy and BAL can also be performed in patients with suspected pneumoconiosis to aid the diagnosis and/or for research purposes to explain the mechanism(s) of the disease. ${ }^{35}$
The results of in vitro, animal, and human investigations support four basic mechanisms in the aetiology of coal workers' pneumoconiosis and silicosis:

1. Direct cytotoxicity of coal dust or silica, resulting in lung cell damage, release of lipases and proteases, and eventual lung scarring.

2. Activation of oxidant production by pulmonary phagocytes, which overwhelms the antioxidant defences and leads to lipid peroxidation, protein nitrosation, cell injury, and lung scarring.

3. Activation of mediator release from alveolar macrophages and epithelial cells, which leads to recruitment of polymorphonuclear leucocytes and macrophages, resulting in the production of proinflammatory cytokines and reactive species and further lung injury and scarring.

4. Detection of growth factors from alveolar macrophages and epithelial cells, stimulating fibroblast proliferation and eventual scarring.

Data obtained from exposed workers lend support to these mechanisms. ${ }^{15}$

Pneumoconiosis is still an important health problem in Turkey. In a survey of 12300 coal workers, approximately $12 \%$ of the miners were found to have pneumoconiosis. ${ }^{4}$ The present study is the first to evaluate the cellular profile in miners in Turkey.

The yield of cells in BAL fluid is significantly dependent on the condition of the prealveolar airway. ${ }^{7}$ Recovery of fluid may markedly be attenuated in subjects with airflow obstruction. ${ }^{8}$ Occupational dust exposure leads to airflow obstruction and focal emphysema adjacent to the coal macule. The instilled BAL fluid may be trapped in the alveolar space in such subjects 
with airflow obstruction and emphysema. ${ }^{6}$ We observed airflow obstruction in all miners, except those with simple pneumoconiosis, compared with the smoker and/or the nonsmoker controls. The amount of recovered BAL fluid was significantly lower in all miners with or without pneumoconiosis than in the non-smoker controls. We detected a significant correlation between the amount of recovered BAL fluid and the total cell count.

The results of BAL in coal workers' pneumoconiosis are controversial. ${ }^{10}$ More inflammatory cells were detected in recovered BAL fluid in subjects exposed to inorganic dust who had asbestosis, coal workers' pneumoconiosis, or silicosis compared with normal controls, although the proportion of lavage fluid returned was similar. Alveolar macrophages dominated these inflammatory cells. Although the proportions of neutrophils were increased in pneumoconiosis, the neutrophils represented a small proportion of the total inflammatory cell populations recovered. ${ }^{11}$ An increased cellularity was observed with a prominent increase in macrophages and some increments in lymphocytes and neutrophils in workers exposed to quartz with or without pneumoconiosis. ${ }^{12}$

Increased cellularity in the BAL fluid in patients with simple pneumoconiosis was detected, but there was no change in white cell count. On the other hand, a striking increase in lymphocyte count was found in three subjects with rapidly developing silicosis and coexistent disorders like connective tissue disorder, sarcoidosis, extrinsic allergic alveolitis, radiation lung, or diffuse interstitial fibrosis. The authors also observed a diminished phagocytic and bacterial activity of the alveolar macrophages on Staphylococcus aureus after 24 hours' survival. $^{13}$

The lymphocyte count was increased in the BAL fluid of a heterogeneous group of patients exposed to organic or inorganic dust. These lymphocytes were activated T lymphocytes and the increment was pronounced in CD8 + T cells. The authors postulated that the monocyte-macrophage system and lymphocytes were activated whether the offending agent was organic or inorganic dust. ${ }^{14} \mathrm{~A}$ raised cell count with relative lymphocytosis, increased permeability, and enhanced interleukin- 6 and decreased interferon- $\gamma$ in the BAL fluid of subjects with idiopathic pulmonary fibrosis and patients with simple pneumoconiosis was demonstrated. ${ }^{15}$

These research data state that a raised cellularity and lymphocytic and/or neutrophilic alveolitis in BAL fluid is frequently found in subjects with pneumoconiosis. We detected an increased cellularity in BAL fluid in miners compared with the non-smoker controls, however, the difference was not significant. In contrast to previous data, we found a significant decrement in lymphocytes in miners with or without pneumoconiosis. As mentioned above, airflow obstruction may account for the lower recovery of BAL fluid and the depletion of lymphocytes in the present study subjects.

In previous research on BAL fluid cellularity there are no definite data on whether the miners with alveolitis were concurrently exposed to inorganic dust. ${ }^{11-13} 16$ The subjects in the present study had all been retired for many years before the study, but the time elapsed was not registered. The cessation of exposure for a long enough period of time may account for the lack of alveolitis.

Although miners are exposed to similar dust with a similar concentration, some never develop pneumoconiosis. However, some develop simple pneumoconiosis with nodular or linear opacities seen on chest radiographs or they further develop PMF characterised by conglomerates besides nodular or linear opacities detected by radiographs. Many cytokines have been investigated to try and discover why some people develop pneumoconiosis and some do not ${ }^{16-18}$; genetic factors might also be involved in its development. ${ }^{19}$

\section{CONCLUSION}

Alveolitis was not a representative feature in Turkish subjects with an occupational history of underground mining, and the BAL fluid cellular profile did not seem to be different in miners with or without pneumoconiosis. Some other factors like genetic predisposition and/or cytokines may be involved in the pathogenesis of pneumoconiosis.

\section{Authors' affiliations}

O Kayacan, S Beder, D Karnak, Ankara University, School of Medicine, Chest Diseases Department, Ankara, Turkey

\section{REFERENCES}

1 Redlich CA. Occupational lung disorders: general principles and approaches. In: Fishman AP, Elias JA, Fishman JA, et al, eds. Fishman's pulmonary diseases and disorders. 3rd Ed. International Edition, 1998: 867-76.

2 International Labor Office. Guidelines for the use of ILO international classification of radiographs of pneumoconioses. Occupational safety and health series. No 22 (revised). Geneva: International Labor Office,

1980.

3 Costabel U, Donner CF, Haslam PL, et al. Occupational lung diseases due to inhalation of inorganic dust. In: Klech $\mathrm{H}$, Hutter $\mathrm{C}$, eds. Clinical guidelines and indications for bronchoalveolar lavage (BAL): report of the European Society of Pneumology Task Group on BAL. Eur Respir J 1990:3:946-9.

4 Numanoğlu N, Gönüllü U, Özdemir Ö, et al. Pulmonary findings and pneumoconiosis in 12300 coal miners. Doğa Turkish Journal of Medical Sciences 1993;19:227-38.

5 Teschler H, Costabel U. Lungenparenchym erkrankungen: Differenzierung mittels bronchoalveolärer Lavage. In: Konietzko N Costabel U, Müller K-M, eds. Generalisierte

Lungenparenchymerkrankungen. Darmstadt: Steinkopff Verlag, 1990: $48-74$.

6 Parker JE, Petsonk EL. Coal workers' lung diseases and silicosis. In: Fishman AP, Elias JA, Fishman JA, et al, eds. Fishman's pulmonary diseases and disorders. 3rd Ed. International Edition, 1998: 901-14.

7 Klech H, Pohl W, eds. Technical recommendations and guidelines for bronchoalveolar lavage (BAL). Eur Respir J 1989;2:561-85.

8 Martin TR, Raghu G, Maunder R, et al. The effects of chronic bronchitis and chronic air flow obstruction on lung cell populations recovered by bronchoalveolar lavage. Am Rev Respir Dis 1985;132:254-60.

9 Banks DE, Chang WWL. Silicosis and coal workers' pneumoconiosis. In: Albert RK, Spiro SG, Jett JR, eds. Comprehensive respiratory medicine. Mosby, 1999: 60.1-6

10 Brichet A, Salez F, Lamblin C, et al. Coal workers' pneumoconiosis and silicosis. In: Mapp CE, ed. Occupational lung disease. European Respiratory Monograph 1999:4:136-57.

11 Rom WN, Bitterman PB, Rennard SI, et al. Characterization of the lower respiratory tract inflammation of nonsmoking individuals with interstitial lung disease associated with chronic inhalation of inorganic dusts. Am Rev Respir Dis 1987;136:1429-34.

12 Bégin RO, Cantin AM, Boieau RD, et al. Spectrum of alveolitis in quartz-exposed human subjects. Chest 1987;92:1061-7.

13 Voisin C, Gosselin B, Ramon P, et al. Bronchoalveolar lavage in pneumoconiosis of coal miners. Cytologic aspects. Rev Fr Mal Respir $1983 ; 11: 455-66$

14 De Araujo AT, Alfarroba E, Costa MFE. The role of monoclonal antibodies in the study of chronic inflammatory respiratory diseases induced by dust inhalation. Eur J Respir Dis 1986;69 (suppl 146):203-10.

15 Lesur OJ, Mancini NM, Humbert JC et al. Interleukin-6 interferon-gamma, and phospholipid levels in the alveolar lining fluid of interferon-gamma, and phospholipid levels in the alveolar lining
human lungs. Profiles in coal workers' pneumoconiosis. Chest 1994; 106:407-13

16 Hayem A, Scharfman A, Laine A, et al. Bronchoalveolar lavage in pneumoconiosis of coal miners. Biochemical aspects. Rev Fr Mal Respir 1983;11:417-26.

17 Vanhee D, Gosset P, Wallaert B, et al. Mechanisms of fibrosis in coal workers' pneumoconiosis. Increased production of platelet-derived growth factor, insulin-like growth factor type I, and transforming growth factor $\beta$ and relationship to disease severity. Am J Respir Crit Care Med 1994; 150:1049-55.

18 Vaillant P, Menard O, Vignaud JM, et al. The role of cytokines in human lung fibrosis. Monaldi Arch Chest Dis 1996;51:145-52.

19 Rihs HP, Lipps P, May-Taube K, et al. Immunogenetic studies on HLA-DR in German coal miners with and without coal worker's pneumoconiosis. Lung 1994;172:347-54. 